\title{
EL SISTEMA DE VALORES DEL CLIENTE EXTERNO E INTERNO EVIDENCIADOS EN EL PROCESO DE ENFERMERÍA
}

Nora Agnes Vega Villalobos*

VILLALOBOS, N.A.V. El sistema de valores del cliente externo e interno evidenciados en el proceso de enfermería. Rev.latino-am.enfermagem, Ribeirão Preto, v. 7, n. 4, p. 39-44, outubro 1999.

Entenderemos valor como una creencia permanente del modo especifico de conducta o estado final de la existencia. Nuestros valores influencian muchos aspectos de nuestras vidas. Es importante distinguir entre los valores que la gente tiene y los valores que ellos dan a los objetos y eventos en su ambiente inmediato. La salud existe como un fin o es una motivación para conseguir felicidad o placer. Forma parte del sistema de valores de un individuo en esa organización llamada hospital. Presentamos un ejemplo para pensar en cómo se vive ese valor llamado salud y reflexionar sobre nuestro propio modo de vivir y ser saludable.

TÉRMINOS CLAVES: valor, organización, salud, vivir

\section{INTRODUCCIÓN}

El marco de referencia de gestión de calidad contempla el sistema de valores del cliente interno, el externo y la influencia de los valores del hospital, esa organización donde se desarrolla el proceso de enfermería.

Para tener el conocimiento del individuo y su familia sobre lo que consideran como vivir y ser saludable hay que observar su comportamiento e inmiscuirse en su pensamiento sobre los valores de su cultura. La experiencia del cliente externo en el hospital pasa por una desestructuración de la personalidad, además de la experiencia concreta de su enfermedad. Y si se tiene que enfrentar a una experiencia nueva como lo es la muerte, más fuerte es el impacto según su sistema de valores.

Discutamos primero porque el proceso de enfermería con el marco de referencia de gestión de calidad tiene que ver con el sistema de valores.

Según CERQUEIRA (1992, p. 3-4) el desarrollo de la calidad tiene influencia de tres subsistemas: 1) el contexto, 2) el abordaje contingencial y 3) las prácticas gerenciales.

1) El contexto se refiere al medio en que la organización y su trabajo están inmersos, al ambiente interno y la relación entre ambos.

2) El abordaje contingencial según el cual la calidad debe ser descrita. Son el sistema técnico, el político y el cultural.

3) Y las prácticas gerenciales básicas utilizadas para desenvolver la calidad: planeamiento, control y mejoría continua. Estos tres componentes pueden ser visualizados en tres niveles: estratégico, táctico y operacional, que integrados permiten administrar la calidad.

El nivel operacional de la mejoría continua es el que posibilita girar el P.D.C.A. (Plan, Do, Check, Act). El Plan es documentar lo que se hace, Do es hacer lo que se dice, Check es evaluar lo que se hace (comparar resultados con lo planeado o sea el momento de la verdad) y Act es corregir o prevenir las fallas (CORREA, 1993, p. 64).

Para efectos del proceso de enfermería, el P.D.C.A. se entenderá como V.I.D.A. Donde $\mathrm{P}=\mathrm{V}$ e indicará la visión o marco de referencia del planeamiento, $\mathrm{D}=\mathrm{I}$ o sea la implementación de las estrategias de acción, $\mathrm{C}=\mathrm{D}$ nos dará el discernimiento del "Momento de la verdad" y A = A que demostrará el ajuste del cuidado.

Entenderemos como "proceso de enfermería" el cambio que implica un cuestionamiento sistemático con una visión que posibilita intervenir en la práctica con estrategias para obtener calidad del cuidado en cada momento de la verdad y evaluar para poder trazar una nueva visión y reiniciar el proceso.

En este proceso el cliente interno(profesional de enfermería), el cliente externo y su familia intervienen en las siguientes condiciones:

\footnotetext{
* Profesora Asociada, Escuela de Enfermería. Universidad de Costa Rica. Pós-graduação em Enfermagem na Universidade Federal de Santa Catarina
} 


\section{Sistema de referencia Contexto Sistema de referencia}

actitudes

actitudes

valores

valores

creencias

deseos

cliente interno

\begin{tabular}{|l|l|}
\hline A & V \\
\hline D & I \\
\hline
\end{tabular}

cliente externo

creencias

deseos

sentimientos

sentimientos

expectativas

expectativas

Fuente: ALBRECHT \& BRADFORD. Momento de la verdad. 1992 , p. 28

El "momento de la verdad" es entendido como aquel instante en el cual el cliente entra en contacto con la atención de su salud y con base en este contacto forma una opinión sobre la calidad del servicio (ALBRECHT \& BRADFORD, 1992, p. 28).

El "momento de la verdad" según el sistema de referencia propuesto por el cliente interno en la Visión del proceso de enfermería transformará la experiencia en algo positivo o negativo. Si lo podemos identificar serán momentos "fundamentales" de la verdad de nuestro cuidado. Existen momentos "especiales" de la verdad como aceptar o no el cuidado, decidir nuevas formas de cuidado, dar las malas noticias y momentos "perpetuos" del cuidado que podemos no acompañar.

En el modelo del "momento de la verdad" intervienen diversidad de factores como contexto, esquema de referencia del cliente externo y su familia y el esquema de referencia del cliente interno (profesional de enfermería). En este esquema de referencia se encuentran los valores.

\section{Sistema de valores}

Según ABBAGNANO (1970, p. 362) encontramos que el valor se sustrae de la alternativa propia de la noción de bien que puede ser interpretada o en sentido objetivo como realidad o en sentido subjetivo como término de deseo. El valor posee un modo de ser objetivo en el sentido de poder entenderse o aprenderse independientemente de la aptitud pero es al mismo tiempo un dato en una cierta forma de experiencia específica.

Rokeach apud LONNER \& MALPASS (1994, p. 184) define valor como una creencia permanente del modo específico de conducta o estado final de la existencia personal o socialmente preferible.

Los sistemas de valores son modificados a lo largo de la vida o sea como la gente toma sus nuevos roles y responsabilidades. Los antecedentes o determinantes de los valores y de los sistemas de valores son complejos y envuelven la cultura, la sociedad, sus instituciones y la personalidad individual.

Nuestros valores influencian muchos aspectos de nuestras vidas, afectados por la manera como construimos y evaluamos las situaciones y las acciones que realizamos en busca de caminos importantes.

El valor es por tanto constantemente reconocido como dotado de tres caracteres: a) la objetividad; b) la simplicidad por la cual es indefinible e indescriptible en el mismo sentido que lo es una calidad sensible elementar; y c) la necesidad o problematicidad.

Esta última es la alternativa que sustituye en el ámbito de la noción de valor la alternativa entre subjetividad y objetividad propia de la noción de bien. Las doctrinas que reconocen la "necesidad" del valor, esto es su carácter absoluto, eterno tienen un estrecho parentezco con las doctrinas éticas tradicionales del fin; al paso que las doctrinas que reconocen la "problematicidad" del valor son estrechamente emparentadas con las doctrinas éticas de la motivación.

Las doctrinas de Scheler y Hartmann (ABBAGNANO,1970) están entre las que afirman la necesidad del valor o sea el fin (felicidad). En la doctrina de la motivación de la conducta el bien se define como objeto de la voluntad humana o de las reglas que la dirigen (placer). La calidad como fin (felicidad) o motivación (placer) en el proceso de vivir de los individuos está fuertemente focalizada en las relaciones con los otros y con la naturaleza, en el proceso de superación de obstáculos que envuelven deseos, creencias, valores y prácticas individuales y colectivas (PATRICIO, 1995, p. 207).

Ahora veamos, la salud es un fin o una motivación de la conducta como el obtener felicidad o placer. Para Diógenes, LVII, 105-6 apud ABBAGNANO (1970, p. 952) la salud es un valor corporal. Y si para CARVALHO \& PEIXOTO (1972) valor es la calidad del que tiene fuerza, valentía, coraje, esfuerzo, mérito o significación exacta de un término; vivir es tener vida, estar con vida, existir, durar, gozar la vida, colocar la subsistencia o los medios de pasar la vida. Saludable es bueno, útil, conveniente para la salud, higiénico, benéfico.

Así tenemos que el cliente externo y el interno (profesional de enfermería) tanto como el hospital poseen un sistema de valores, esto es fines o motivaciones que pueden ser congruentes entre sí o contrarios de acuerdo al sistema de referencia con que se mire. $Y$ al desarrollar el proceso de enfermería van a influir en la calidad del cuidado.

Para tener el conocimiento de lo que es vivir y ser saludable hay que recurrir al pensamiento de cada individuo dentro de su cultura. El hospital es una organización que tiene su propia cultura. 


\section{Los valores en la organización}

Quién es ese cliente ciudadano en la organización llamada hospital y qué sistema de valores tiene ese cliente dentro de esa organización? Veamos primero el hospital donde se manifiesta una cultura específica.

La cultura tiene por finalidad proponer un sentido a las actividades del hombre (Joly, p. 87, apud CHANLAT et al., 1992). Podemos entenderlo mejor por los trazos culturales que marcan las actividades humanas, el cotidiano de los miembros de una cultura en relación a la alimentación, al lenguage, a la higiene, al tiempo y a la muerte. Los trazos culturales suministran una visión de estructura subyacente, más compleja pues representa el sistema de creencias. Este sistema provee las llaves para interpretar comportamientos que a primera vista nos parecen extraños, irracionales pero de los cuales no escapamos.

La organización, en este caso el hospital que es nuestro contexto cultural constituye el cuadro social de referencia en el cual se inscriben las actividades humanas; que tienen de un lado el sistema estructural-material y de otro el subsistema simbólico.

El subsistema estructural-material remite a las condiciones ecogeográficas, a los medios materiales, dado en el abordaje contingencial por el sistema técnico donde se establecen los procedimientos en manuales con esquemas de distribución de trabajo. Y el sistema político que marca el poder, el ejercicio de la autonomía. El poder pasa a existir entre los hombres cuando ellos actuan juntos, y desaparece en el instante en que ellos se dispersan (ARENDT, 1993, p. 212). Y el subsistema simbólico remite al universo de las representaciones individuales y colectivas que dan sentido a las acciones, interpretan, organizan y legitiman las actividades y las relaciones que hombres y mujeres mantienen entre sí. Dado por el sistema cultural en el abordaje contingencial, donde se manifiestan los sentimientos, creencias, expectativas, se ejerce la ciudadanía, la negociación. La interacción entre estos dos subsistemas, mediatizados por las relaciones de poder contribuye para identificar el orden organizacional (CHANLAT, 1992, p. 40).

Este orden organizacional es por definición siempre inestable. Las tensiones, los conflictos, la incerteza, la ambigüedad, las desigualdades, las contradicciones de origen exógenas y endógenas variadas se encargan de alimentar esta inestabilidad.

El hospital que es una organización constituye el contexto de la vida de muchos individuos, ya sean empleados (cliente interno) o clientes externos y ejerce influencia sobre la conducta individual. El cliente externo que procura el hospital para ser atendido está profundamente ligado a la naturaleza y a la cultura que lo envuelve y que él transforma. Dispone de una autonomía relativa, está marcado por sus deseos, sus aspiraciones y sus posibilidades, dispone de un grado de libertad para construir sus relaciones con los otros. Es un ser de pensamiento y de palabra, dentro de un tiempo y un espacio; es un ser simbólico para quien la realidad debe tener un sentido envuelto con el sufrimiento y el placer que ofrece la existencia. La experiencia del cliente externo en el hospital "pasa por cierta desestructuración de la personalidad (Joly, p. 92 apud CHANLAT et al., 1992) además de la experiencia concreta de su enfermedad. Esta desestructuración causada por la experiencia intercultural es la primera causa de la dificultad del sistema de valores del cliente porque penetra en su identidad personal, en sus propios fundamentos. La experiencia concreta de su enfermedad es construida culturalmente.

Esta relación del individuo con la enfermedad es una experiencia no solo corporal sino pensada en la tradición cultural. Como la cultura piensa la enfermedad, es decir los valores de la cultura, la cuestión de la afectividad. Las enfermedades como experiencias afirman lazos de su cuerpo con sus deseos, necesidades. La experiencia es una cuestión de voluntad, de deseos, la persona se siente enferma y procura el tratamiento porque tiene un deseo de recuperación.

Es bueno trabajar con la historia de la enfermedad, la experiencia de la enfermedad. Escuchar a la persona como cuenta la enfermedad, cómo fue, cómo inició, dónde fue, cómo sintió. Cada persona construye su propia experiencia. Esa narrativa o historia orienta sobre el significado de los valores asociados con las enfermedades y el sufrimiento.

El sistema de valores del cliente interno (profesional de enfermería) es también influenciado por la cultura en la construcción de la experiencia de la enfermedad, por la cultura del hospital y de su profesión. Sufre también desestructuración de su persona y eso se manifiesta al intervenir con el cliente externo.

\section{OBJETIVO}

Describir la manifestación del sistema de valores del cliente externo y el interno en el momento de la verdad del proceso de enfermería.

\section{METODOLOGÍA}

La experiencia de la enfermedad y la identificación del sistemas de valores de las personas (clientes internos y externos) en una organización hospitalar es presentada como reflexión en el caso a 
seguir. El marco de referencia de gestión de calidad nos muestra al ejecutar el proceso de enfermería en un niño con diagnóstico de cáncer nasofaríngeo y su padre, el sistema de valores manifestado en las intervenciones dentro de esa organización llamada hospital.

El marco de referencia de gestión de calidad para desarrollar el proceso de enfermería, (V.I.D.A.) como lo señala VEGA VILLALOBOS(1996) considera la salud como un compromiso con la propia vida y la de los demás. Para eso debe procurarse el desarrollo de las potencialidades físicas, psicológicas, sociales, enfrentando los riesgos y los conflictos, también disfrutar de los valores estéticos como el placer, la tactibilidad, la colectividad en armonía con el universo, haciendo las cosas siempre con el ansia de querer y poder evoluir. La salud será objeto de pesquisa constante para tener la prevención con medidas de poder y negociación dentro de lo real e imaginario usando recursos tecnológicos y educativos.

Y "calidad del cuidado" aquella que permite que el sistema de referencia del cliente externo y el interno (profesional de enfermería) o sea sus creencias, expectativas, valores, sentimientos y deseos sean manifestados y tomados como fundamento en el contexto del proceso, en el que ambos poseen autodeterminación, pueden solicitar el cuidado cuando lo consideren necesario y el profesional lo puede ofrecer según le sea solicitado. Esta autodeterminación será dada por el ejercicio de la ciudadanía, donde el cliente externo es capaz de elaborar su propio proyecto de calidad de vida, de evolución, de cambio en medio de la enfermedad, de la incerteza para obtener placer y felicidad, paz interior.

Específicamente cómo se manifiesta el sistema de valores del cliente y del profesional de enfermería en el contexto del hospital al compartir el poder, negociar o pedir el cuidado, desarrollar las potencialidades con placer y felicidad, construir modos de satisfacer las necesidades y participar en los ajustes ante los desafios manifiestos y ocultos de un modo de vivir saludable.

Se describirá como se expresa el concepto de salud en el "momento de la verdad" de una experiencia de enfermedad en el marco de referencia de gestión de calidad.

\section{Una experiencia de enfermedad en el hospital, sistema de valores evidenciados}

Veamos cómo se dió la experiencia de la enfermedad en el "momento de la verdad" vivido según la mirada de cada ítem propuesto por el concepto de salud: Compartir el poder: asumir el cuidado de su espacio

$\mathrm{Si}$ el valor es la creencia de lo que es la conducta socialmente preferible, el padre del niño se manifestó como alguien que experimenta la enfermedad como parte de lo que se tiene que vivir. Asumia el cuidado por su hijo, más se sentía impotente para controlar la desesperación del dolor. Casi siempre solicitaba lo que necesitaba. Se relacionaba con los médicos pero desconozco como compartía el poder de decisión.

Quizá no es medible porque no lo expresaba pero observé conformidad con la calidad del cuidado brindado a su hijo. Manejaba cierto poder. Aceptaba y agradecía las proposiciones para escoger la comida, para hacer un horario de administración del medicamento del dolor. No le observé expresión de disgusto, mal humor, inquietud, sobresalto por las respuestas inefectivas al tratamiento de su hijo.

Pedía lo que quería y se le complacía, parecía ser más compasión que paralelismo en el poder para cuidar y pedir. Cómo medir el poder compartido, la actitud de los clientes internos, parecía deberse a "no hay nada que hacer", solo dar lo que se puede. La participación en las decisiones del cuidado del niño fue amplia porque no se ejerció ninguna restricción.

Hay en el ambiente una sensación de ceder porque la impotencia ante las manifestaciones del niño prevalecen. Este dejar hacer, cumplir las demandas del niño da la impresión de ser acrítico, de poca autodeterminación. Parece existir impotencia en el padre para hacer prevalecer la concepción de salud y vivir saludablemente como motivación de la conducta.

Es difícil identificar y explotar las potencialidades positivas físicas o sicológicas. Es un momento "perpetuo" de la verdad que podemos no acompañar.

\section{Negociar o pedir el cuidado}

El padre del niño considera la salud como una necesidad, un fin de todo ser humano y fue hasta que llegó al hospital pediátrico cuando obtuvo lo que necesitaba para su hijo. Hay una queja íntima, personal en él de que procuró siempre negociar la mejor atención para el niño pero no encontró la respuesta exacta hasta que llegó a este hospital. La negociación actual está más cercana a la situación del dolor, de la angustia, del temor. El padre espera que los demás decidan sobre lo que es prioritario para el niño. No está preparado para comprender que quienes establecen las prioridades son ambas partes.

El niño negocia su cuidado por medio del llanto. El padre sabe procurar lo que precisa pero su hijo no acepta nada para mejorar. Será que llamando la atención disminuye su temor?.

La intervención indica que casi instintivamente buscan lo mejor, aunque no saben con claridad que es. Las relaciones de negociación para alivio del dolor se dan en una lucha silenciosa con respecto al poder médico. La negociación se da más en un plano emocional que físico pues no precisa de negociación para realizar los cuidados básicos ya que el padre lo lleva a caminar, le 
mide la orina, le da de comer, le corta las uñas. El padre participa en la decisión de lo que cree que es más urgente para el niño, negocia con el personal según lo que sus posibilidades de conocimiento le hace comprender qué es lo mejor.

En realidad no se si esta experiencia es positiva o negativa. La negociación implica un concepto de salud claro, de calidad de vida esperado a pesar de la enfermedad para poder independizarse en su cuidado. Es un momento "especial" de la verdad que no asumen el cliente externo y su padre.

\section{Desarrollar las potencialidades con placer y felicidad}

La salud tiene implícito un compromiso con la propia vida. La vida implica un proceso de evolución o sea que tiene cambios en procesos continuos de creatividad. Ningún cambio se da en forma aislada. Por eso a pesar de que la enfermedad evoluciona el niño también lo hace en aspectos sicológicos, sociales.

En medio de la enfermedad y del ambiente hospitalario es factible buscar el desarrollo de otras potencialidades con placer y felicidad. Pero qué sucede? Es difícil compartir estos pensamientos con el padre y el niño, pues las demandas de este no lo permiten.

A veces da la impresión de que el niño quiere disfrutar del momento pero parece que el dolor no ayuda, como si las horas no avanzaran y la queja continúa. Será posible disfrutar de un espacio de calma y tranquilidad sin que esté sedado, de verlo sereno y consciente. El padre desea que evolucione pero respeta el ritmo para hacerlo. Solo podrá mejorar si se insiste en que coma, que camine, si se es firme con su cambio.

La intervención indica que profundizar en medidas de placer y satisfacción es un proceso lento. Es díficil tener satisfacción con una mejoría que no llega, un cambio que no se percibe, un tiempo que parece que estar parado. Los cuidados realizados solo son para prevenir el aumento de la queja por dolor. Es imprescindible que el niño participe sus sentimientos, para identificar los medios que le permitan evoluir dentro de sus condiciones de salud.

Toda la conversación gira alrededor del dolor lo que hace imposible profundizar en otras medidas para que pueda evoluir su situación actual. El único sentimiento compartido es el de intranquilidad, el de desasosiego. La atención gira más hacia el lado físico de la enfermedad que hacia el sentimiento de temor, angustia que posee. El diálogo convierte al niño en alguien más demandante, quejumbroso.

Puede ser una experiencia positiva o negativa que no da para preguntar. O un momento "perpetuo" que no podemos acompañar.

\section{Construir modos de satisfacer las necesidades}

Para que el padre y el niño construyan modos diferentes de satisfacer las necesidades fue necesario conocer vivencias del niño, para identificar condiciones o elementos que ayudasen a la modificación del comportamiento. Pero fue inútil. Se estimulaba al niño a expresarse pero solo se quejaba.

No se encontró una fórmula mágica para satisfacer la queja constante del dolor. El padre siempre procuraba con calma y paciencia, sin desespero que satisfaciera sus necesidades. En cuanto al dolor buscaba diferentes modos de tratarlo pero sin efectividad.

La intervención del cliente interno era para profundizar en otros modos de satisfacer lo que precisaba, en contar con una acción mutua para cuidarlo pero sin éxito.

Fue difícil profundizar en medidas alternativas de alivio del dolor porque no se contaba con la participación del niño. El padre consideraba que la accesibilidad de los recursos de la institución no era problema sino la aceptación del niño a los modos de tratarlo. La resistencia del niño a la construcción y el experimentar de otros modos de alivio del dolor hizo imposible satisfacer sus necesidades.

La construcción de un modo de vivir saludable no es congruente con la experiencia de la enfermedad actual. La única motivación giraba alrededor de la agonía, profundidad del dolor sin dar lugar a la construcción de otras formas para expresarse. La impotencia convierte en "perpetuo" el momento de la verdad ya que no se puede acompañar.

\section{Participar en los ajustes ante los desafíos manifiestos y ocultos de un modo de vivir saludable}

El sistema de valores influencia muchos aspectos de nuestra vida, como tomamos nuevos roles y responsabilidades. La salud para el niño no sería precisamente un fin sino que la participación en los ajustes dentro de la enfermedad serían para tener modos de vivir saludable.

El niño no quiere tener desafíos, no acepta dialogar a pesar de la insistencia para que participe en otras formas de enfrentar el alivio del dolor. Parece que los desafíos son díficiles de enfrentar, como que el dolor no va a acabar nunca solo acepta el medicamento como medida de alivio del dolor. El padre enfrenta con esperanza pero con calma el que mejore para poder irse, se siente útil y le encuentra sentido a la compañía, sabe que tiene el apoyo de otras personas para enfrentar los desafíos.

La intervención se hace para buscar lo mejor en este período que aunque está en la esfera de lo díficil, no es imposible.

El padre está muy interesado en buscar y probar otros medios de enfrentar el dolor, espera con calma la reacción del niño, porque aunque cuenta con otras personas para enfrentar el problema nada se puede hacer si el niño no participa. La reacción inmediata de alivio 
del dolor que experimenta al ser administrado el medicamento hace sospechar que sus quejas sean causadas por algo más profundo. Después de días de insistencia con cooperación del padre en el diálogo ha sido posible un pequeño rasgo de participación para probar otras formas de alivio del dolor.

Se han vivido momentos "especiales" de la verdad al no participar en los desafíos pero parece ser al cabo de los días una experiencia positiva, como que fue posible cambiar a un momento "fundamental" de la verdad, a participar en su propio proyecto de vida.

\section{CONSIDERACIONES FINALES}

El compartir el poder, asumir el cuidado de su espacio aunque las decisiones no se consideren justas no pareció ser precisamente lo que ocurrió sino una libertad impuesta por el diagnóstico médico.

La negociación para pedir el cuidado dio la impresión de ser una situación de oportunidad. Los pobres conocimientos sobre salud no le permitieron buscar la emancipación para obtener calidad de vida, por lo menos en la visión del cliente interno.

El desarrollo de potencialidades se dio pues la evolución de toda vida continua pero no precisamente se obtuvo con placer y felicidad. Para construir modos de satisfacer las necesidades de un cliente es indispensable que nazca la inquietud de él mismo. No puede ser una acción impuesta y si su sistema de valores no lo considera pertinente no se puede construir un modo de vivir saludable en medio de la enfermedad. La participación en los ajustes ante los desafíos manifiestos y ocultos fue difícil sobre todo cuando la cultura no ha preparado par que se busquen a pesar de las circunstancias formas de vivir saludablemente.

El niño tuvo autonomía para solicitar el cuidado de forma poco saludable. Su ciudadanía no se ejerció a plenitud pues no se dominó la causa de su dolor. Por lo tanto la evolución del cuidado con calidad y el vivir con placer y felicidad estuvo restringido al sistema de valores del cliente y su padre, al de la organización hospitalar y al profesional que lo cuidó.

\section{THE SYSTEM OF VALUES OF EXTERNAL AND INTERNAL CLIENTS EVIDENCED IN THE NURSING PROCESS}

We shall understand value as a permanent belief on the specific way of conduct, or the final state of existence. Ours values influence many aspects of our lives. A distinction must be made betwen a person's own values and those values people attribute to objects and events in their inmediate environment. In this way, health exists as an end, or becomes a motivation to assure happiness or pleasure. It makes part of the system of values of an individual within the organization called hospital. We present an example such as to make us to reflect on how this value called health can be experienced and also on our own way of living and being healthy.

KEY WORDS: value, organization, living

\section{REFERENCIAS BIBLIOGRÁFICAS}

01. ABBAGNANO, N. Dicionário de filosofia. São Paulo: Mestre Jou, 1970.

02. ALBRECHT, K.; BRADFORD, L.J. Serviços com qualidade: a vantagem competitiva. Sao Paulo: Makros Books, 1992.

03. ARENDT, H. A condição humana. Rio de Janeiro: Forense Universitária, 1993.

04. CARVALHO, J.; PEIXOTO, V. Pequeno dicionário da língua portuguesa. São Paulo: LISA Livros Irradiantes, 1972.

05. CERQUEIRA, E.P. de. Paradigmas da qualidade. Rio de Janeiro: Imagem, 1992.

06. CHANLAT, J.F. (coord). O indivíduo na organização: dimensões esquecidas. Tradução e adaptação Arakcy M. Rodríguez et al. São Paulo: Atlas, 1992.
07. CORREA, P.A.M. Qualidade total, da visão à sistematização. Rio de Janeiro: Imagem, 1993.

08. LONNER, W.; MALPASS, R. Psychology and culture. Boston, EUA: Allyn and Bacon, 1994.

09. PATRÍCIO, Z.M. A dimensão felicidade-prazer no proceso de viver saudável individual e coletivo: uma questão bioética numa abordagem holísticoecológica. Florianópolis, 1995. Tese (Doutorado)

- Universidade Federal de Santa Catarina.

10. Vega Villalobos, N.A. A caminho da melhoria contínua no cuidado de enfermagem pediátrica. Florianópolis, 1996. Dissertação (Mestrado) - Universidade Federal de Santa Catarina. 